\title{
UYGUR ŞAİR BOĞDA ABDULLA
}

\begin{abstract}
$\ddot{O} \mathbf{z}$
Boğda Abdulla, Çağdaş Uygur edebiyatının yetiştirdiği öncü şairlerden biridir. Şiire getirdiği yeni ve cesur adımlarla Uygur şiirine yön vermiş önemli bir şahsiyettir. Şiir yazmaya başladığ 1 ilk yıllarda çocuk şiirleriyle tanınmıştır. Sanatının olgunluk döneminde şiirlerinde folklorik unsurlardan yararlanmıştır. Bu yönüyle Çağdaş Uygur şiirinde kalıcı izler bırakmayı başarabilmiştir. $\mathrm{Bu}$ yazıda Boğda Abdulla'nın hayatı, edebî kişiliği, şiire getirdiği yenilikler ve şiirleri üzerinde durulacaktır. Boğda Abdulla'nın değişik zamanlarda yazdığı şiirlerden bazıları "Qedimiy Yarğolda Keçküz" adlı kitapta toplanmıştır. Şairin edebî kişiliğini değerlendirirken genellikle bu eserde yer alan şiirleri dikkate alınmıştır.
\end{abstract}

Ahmet KARAMAN*

Anahtar Sözcükler: Boğda Abdulla, Uygur şiiri, çağdaş Uygur edebiyatı.

\section{THE UIGHUR POET BOGDA ABDULLA}

\begin{abstract}
Bogda Abdulla is one of the leading poets who was raised in modern Uighur literature. He is an important personality in terms of giving nem and brave direction to the Uighur poem. He is noted for children poems which he wrote during his first year in poetry. He benefits from folkloric elements in his poems during the maturity term of his art. On that sense, he achieved to leave his marks in the Modern Uighur poem. This article will discourse on the life of Bogda Abdulla, his literary personality, his innovation brought to the poem, and his poems. Some of the poems which Bogda Abdulla wrote in the different times are collected into the book called "Qedimiy Yargolda Keçküz”. The literary personality of the poem is evaluated, generally through the poems in this book.
\end{abstract}

Keywords: Bogda Abdulla, Uighur poem, modern Uighur literature.

\section{Hayatı ${ }^{1}$}

Çağdaş Uygur edebiyatına önemli katkılar sağlayan Boğda Abdulla 1941'de Çin'in Kansu eyaletinin merkezî şehri olan Lanzhou'da tüccar bir ailenin çocuğu olarak dünyaya gelmiştir. Ailesi ile birlikte daha sonra Urumçi’ye yerleşen şair 1960 yılına kadar Urumçi 2. İlkokulu ve Urumçi Tecrübe Ortaokulunda okumuştur. 1960 ile 1965 yılları arasında Şincan Üniversitesinin Edebiyat Fakültesinde okumuştur. Eğitimi bittiğinde Şincan Üniversitesi Edebiyat Fakültesinde öğretim elemanı olarak göreve başlayan Boğda Abdulla, daha sonra profesörlüğe yükselmiştir.

\footnotetext{
* Yrd. Doç. Dr.; Afyon Kocatepe Üniversitesi, Fen Edebiyat Fakültesi Çağdaş Türk Lehçeleri ve Edebiyatları Bölümü, ahkaraman03@gmail.com.

${ }^{1}$ Şairin hayatı hakkında bilgiler "Milletler Neşriyati. (2006). Uyg்ur Edebiyati Tarixi 4-1.Béyciñ: Milletler Neşriyati (s. 286-295)" adlı eserden özetlenerek alınmıştır.
} 
Boğda Abdulla'nın bugüne kadar Bahar Ġunçiliri (1978), Yelken ( 1983), Çüş Köridu Bir Tüp Anargül (1988), Qiz Qelesi (1993), Salg̀a Téşi (1998), Şéir Meñgü Axirlaşmaydu (2002), Yéziqçiliq Tog̀risida (1983), Yéziqçiliq İlmi (1996), Şéiriyettiki Boşluq (2004), Komzek Kötürgen Qiz (2004) adlarında yayımlanmış şiir kitapları, bilimsel eserleri ve eserlerinden seçmeler bulunmaktadır. Şairin edebî kişiliğini ortaya koymak için "Qedimiy Yarg̉olda Keçküz" adlı şiir kitabında yer alan şiirleri değerlendirilmiştir. Bu eserde 1964-2008 yılları arasında yazdığı yüz yirmi yedi şiiri yer almaktadır.

\section{Edebî kişiliği}

Boğda Abdulla sanat hayatına 1954 yılında "Şincañ Yaşliri” (Şincan Gençleri) adlı gazetede yayımlanan “Déhqan Qizliri Heqqide Qoşaq” (Çiftçi Kızları Hakkında Koşak) isimli şiiriyle başlamıştır. Şiire başladığı yıllarda, yazdığı çocuk şiirleriyle tanındı. Çocuklar için yazdığı şiirlerdeki tasvirlerin ilgi çekici olması, şiirlerin kısa, dilinin akıcı ve çocukların diline yakın olması, şiirlerin hatırlanma ve anlaşılmasının kolay olması ona 1950 ile 1960'lı yıllarda çocuk şiirleri sahasında haklı bir şöhret kazandırmıştır. Ancak ona şiirde asıl şöhreti getiren ve şair kimliğini oluşturan şiir, 1960’lı yılların ortasında yazdığı "Çog̉luq Balladisi” (Ateşli Destan) isimli şiiridir. 1970'li yıllardaki siyasi ortam şairlere çeşitli kısıtlamalar getirir. Bu dönemde "Cilg̈idin Çoqqilarġa" (Dereden Tepelere), "Mecnuntalniñ Tégide" (Salkımsöğüdün Altında), "Bulbulni Solima Qepezge" (Bülbülü Koyma Kafese), "Kayima Ana" (Sinirlenme Ana) gibi lirik şiirlerin yanında "Güldestixan", "Meryem" gibi destanları da yazmıştır. Boğda Abdulla bu eserlerde realist bir bakış açısıyla Uygur halkının durumunu tefekkür etmiştir.

1980 yılından itibaren Boğda Abdulla'nın şiir anlayışında yenilikler görülmektedir. 1980 ve 1990’l1 yıllar, şairin en verimli olduğu ve edebî kişiliğinin olgunlaştığı bir dönemdir. Boğda Abdulla kendi şiir anlayışını şöyle dile getirir: "Devrin özelliklerine göre şiir de yenilenmelidir. Biz fikirleri özgürce ve tam ifade edecek yeni şiiri cesaretle yazmalıyız." (Sultan, 2009: 127).

Şair bu dönemde yazdığg "Anican, Anican Yaşigiin Uzaq”, “Ana”, “Turpan Qesidisi”, "Gül ve Muqamçi”, “Çüş Köridu Bir Tüp Anar Gül”, "Qaġa Heqqide Rivayet”, “Ör Kişiñni Bergin Tögiler”, “Şéiriyet İlahi”, "Yaz Yamġuri”, "Bir Rivayet”, “Qiz Qelesi”, "Muqam” gibi şiirlerde insan, tabiat ve hayat hakkındaki özgün ve derin fikirleriyle yenilik peşinde koştuğunu açıkça ortaya koyar. Bu şiirler, şairin edebî kişiliğini en güzel yansıtan şiirlerdir. Şiirdeki tasvirleri, basit tabiat olaylarını çok farklı bir gözle süzüp onlara yeni ve derin anlamlar yüklemesi her kesimden okuyucuyu etkilemektedir. Tabiatı şiir için önemli bir kaynak olarak gören şair, tabiatın her noktasını şiirlerine ilmik ilmik işlemiştir. Şair için diğer ilham kaynakları 
insan ve hayattır. Şair, şiirlerinde okuyucuyla dertleşir, onlara felsefi görüşlerini, duygularını ve hayat tecrübelerini aktarır. Ana adlı şiirde bu durum açıkça görülür:

Toqsanġa ulaşti,

Közi xireleşti,

Tonumaydu gahida séni,

Séni çaqiramaqçi bolup

Çaqiridu başqa birini,

Başqa biri çaqirandek.

Toqsan yaz,

Toqsan küz,

Toqsan qiş,

Toqsan etiyaz,

Ötüp ketti

Mañliyigga iz sélip,

Ötüp ketti sudek

Emdi,

Tétikliki yoq

Burunqidek.

Yer aylinar,

Vaqit uçar,

Bügünniñ bosugisisida

Ete saqlap turar.

Şundaq,

Qériydu barçe:

Ademmu,

Derexmu,

Quşlarmu...
Doksana ulaşt1

Gözü donuklaştı

Tanımaz bazen seni

Seni çağıracak olsa

Çağırır başka birini,

Başka birini çağırmış gibi

Doksan yaz,

Doksan güz

Doksan kış,

Doksan bahar

Geçip gitti

Alnına iz bırakıp,

Geçip gitti su gibi

Şimdi

Çabukluğu yok

Eskisi gibi

Dünya döner

Vakit geçer

Bugünün basamağında

Yarın bekler

Bunun için

Yaşlanır her canlı

İnsan da,

Ağaç da,

Kuşlar da...

"Ana" şiiri, şairin şiire bakışının özetidir. Uygur halk edebiyatı çizgileriyle yenilikçi anlayışın sentezlendiği bu şiirde, Rus şiirinde sıkça görülen merdiven dize özellikleri de görülür. Dizelerin uzunlu kısalı sıralanması hayatın inişli çıkışlı olmasıyla ilgilidir. "Doksan yaz, doksan güz, doksan kış, doksan bahar; dokuz ay, dokuz gün, dokuz saat, dokuz dakika" merdiven basamakları şeklinde düzenlenerek hayatın farklı dilimlerini göstermektedir. Şair, yeni şiiri cesaretle söyleme maharetini bu eserinde açıkça göstermiştir. 
Şairin 1980'li yıllarda yazdığı kısa ve yeni tarzdaki şiirleri dikkat çekmiştir. Boğda Abdullah'ın şair olarak yetişmesinde Rus şairi Lermantov, Puşkin, Özbek şairi Hamit Alimcan, Kazak şairi Abay’ın önemli rolü olmuştur (İnayet, 2000: 243).

1990’l1 yıllardan sonra şair, yönünü geleneğe çevirir. Bu dönemde yazdığı şiirler; efsaneler, halk destanları gibi folklorik unsurlarla bezenmiştir. Halk edebiyatının izinden giden şair “Qag̉a Heqqide Rivayet” (Karga Hakkında Efsane), "Enber Heqqide Rivayet” (Anber Hakkında Efsane), "Sündük Heqqide Rivayet” (Kuş Hakkında Efsane), "Quyun Heqqide Rivayet” (Kasırga Hakkında Efsane), “Aq Qu Heqqide Rivayet” (Ak Kuğu Hakkında Efsane) gibi çağdaş anlatılar vasıtasıyla yepyeni fikirleri okuyucuyla paylaşır. Şair, bu tarz şiirlerinde geleneğin yöntemini kullanarak daima 'yeni’nin peşinde olduğunu göstermiştir. Aqqu Heqqide Rivayet adlı şiirde aynı zamanda milletin tek yürek, tek nefes olmasının önemine dikkat çeker:

AQ QU HEQQIDE RIVAYETAK

Aq ve pakiz

Bir cüp aq qu

Tépişqanda

Béşimiz baş bolsun dep,

Ayağimiz taş bolsun dep,

Teñ uçarmiş,

Teñ qonarmiş.

Qaysibiriniñ bağrini

Qan qilip oq, bolmisa çare,

Saq qalgini pir-pir aylinip

Pelekke çiqip,

Andin özini yerge atarmiş

Bolmaq üçün pare ve pare.

\section{KUĞU HAKKINDA RIVAYET}

Ak ve temiz

Bir çift ak kuğu

Buluştuklarında

Başımız baş olsun deyip

Ayağımız taş olsun deyip

Birlikte uçarmış,

Birlikte konarmış.

Herhangi birinin bağrını

Kanatsa kurşun, çaresiz kalsa

Sağ kalanı pır pır dönüp

Göğe çıkıp

Oradan kendini yere atarmış

Olmak için parça parça.

Bu dönemde yazdığı "Salġa Téşi”" (Sapan Taşı) sadece şairin sanat anlayışını değil Çağdaş Uygur edebiyatının geldiği noktayı göstermesi bakımından da önemlidir. Boğda Abdulla bu şiirinde Taklamakan ve Tarım Havzası gibi kadim coğrafyaları Uygurların şanlı geçmişini dile getirmek için kullanır. Geçmişin ihtişamı bir senfoni uyumuyla okuyucuya fisıldanır:

Muqeddes derexke çigilgen lata

Arzu-ümidniñ bayraqçisidek

Qoçqar müñgüzi şamalda öñgen,

Epsunsiz dunyaniñ cakarçisidek.
Mukaddes ağaca bağlanan çaput

Umutların bayrağı gibi

Koç boynuzu rüzgârda bozulmuş,

Büyüsüz dünyanın habercisi gibi 
Qaytar ademler tugg-şadig̉a,

Roh yuyulup turidu qumluqta.

Sabiyliktin başlinar nepes,

Gülhan aylanġandek altunga otta

Kéçe, qumluqniñ qarañgusida

Kélidu yavayi ceñlerdin sada.

$\mathrm{Bu}$ eqildin ġeyri körünüş,

Körsetme Xuda!

Yavayi taş öñkürler öçken,

Körüner Miñ Öylerniñ boyiqi ara.

Köçer andin kiyiklerniñ közige

Nohqa tutişidu bara-bara
Döner insanlar

Ruh yikanır kumlukta

Çocukluktan başlar nefes

Külhan benzemiş altına ateşte

Gece, kumluğun karanlığında

Geliyor vahşi savaşlardan ses

$\mathrm{Bu}$ akıl dışı manzarayı

Gösterme Allahım!

Yabanî taş mağaralar yok olmuş

Görünür Bin Evler'in boyası arada

Geçer oradan geyiklerin gözüne

Nuh'a ulaşır gide gide

"Salġa Téşi” adlı şiir, dileğin yerine gelmesi için ağaca bez bağlama gibi folklorik unsurların yanında Uygurların tarihî miraslarından da izler taşır. Şiirde geçen "(Qizil) Miñ Öyler” (Kızıl Bin Evler) Uygurların Budizm'e inandıkları dönemde, rahiplerin toplandıkları ibadethanelerdir. $\mathrm{Bu}$ ibadethanelerin duvarına çizilen resimler, Budizm güzel sanatları arasındadır ve Uygurların çok kıymetli yadigârlarındandır (Veli, 1985: 1).

Boğda Abdulla'nın edebî kişiliğini oluşturan belirli özellikler vardır. Bunlardan biri, şairin öznel dünyası ile nesnel hayat arasındaki nazik ilişkiyi ustaca ele almasıdır. Öznel duygularıyla hayatın nesnelliğini mükemmel bir şekilde somutlaştırır. Bir kalıpta ustaca eritip tek parça haline getirdiği öznellik ile nesnellik, şairin şiirdeki maharetini ortaya çıkaran önemli bir olgudur. "Bügün ve Ete" adlı şiirinde dünyayı objektif bir gözle izleyip sonra iç dünyasına döner. Şair dünyadaki kavga, zıtlık ve amaçsızlıktan rahatsızdır. Böyle bir dünyadan sıyrılarak güzelliklerle dolu, gayesi olan iç dünyasına sığınır. Şiirde, dış dünyadan içe dönüş, bir sıçrayıştır ve şairin ruhundaki boşluğu gösterir. Bugün - yarın, baht - felaket, gülme - ağlama gibi zıtlıklar okuyucuyu şiir üzerinde düşünmeye sevk eder. Yeni Uygur şiirinde "guñgaa" olarak adlandırılan ve anlamı müphem olan bu tarz şiirler edebî maharet olarak görülmektedir:

\section{BÜGÜN ve ETE}

Aqillar etini oylaydu bir-bir,

Beziler bügünge tamamen esir,

Bext veya halaket

Ete démek muqerrer teqdir.

Külke héçkimdin miras qalmig̉an,

Héçkim yigini sétip almig̉an,

\section{BUGÜN ve YARIN}

Akiller yarını düşünür bir bir

Bazıları bugüne tamamen esir

Baht ve felaket

Yarın demek takdir olunmuş kader

Gülüş kimseye miras değil

Kimse ağlamayı satın almaz 
Avuniñ keynide mavu bar,

Şundaq çörgilep turidu cahan.

Ularġimu kélidu ete,

Belki saña kelgendin beter.

Yalġuzluqta köñül şundaq sap,

Özüñniñ dunyasi güzel neqeder.
Onun arkasinda bu var

Böyle döner durur dünya

Onlara da gelir yarın

Belki sana geldiğinden beter

Yalnızlıkta gönül çok saf

Kendi dünyası ne kadar güzel

Şairin edebî başarısının ortaya çıkmasında önemli bir kaynak da halk edebiyatıdır. Halk edebiyatının şekil ve üslup gibi pek çok özelliğinden yararlanmıştır. Folklorik unsurlarla bezediği şiirlerinde halk edebiyatının izleri kolaylıkla fark edilebilir. "Gunahkar Kélin" (Günahkâr Gelin) adlı şiirde, gece nöbetinde uyuduğu için obası düşman tarafından yok edilen günahkâr bir gelinin taşa dönüşü anlatılır. Marmara Denizi kıyısında yazdığg "Kız Kalesi” adlı şiir ise, onun yalnızca doğup büyüdüğü toprakların efsanelerinden değil Türk efsanelerinden de haberdar olduğunu gösterir:

\section{QİZ QELESİ}

Qedimki bir padişah

Yilan körüp çüşi buzulup,

Arzuluq qizini cabdundurup,

Baqqanimiş neççe-neççe yil,

Boġuz içige qele saldurup.

Bir küni,

Bir béliqçi kémini heydep,

Sévet-sévet üzümni yüklep,

Bargininida méve satqili,

Ussap-ussap üzüm alġan qiz,

Biraq közdin ketkendek çetlep,

Bir sévettin çiqip bir yilan,

Neşter urup qoyġanmiş püklep.

Şundin béri

Siñgen bu nam "Qiz Qelesi" dep.

Rivayet deymiz bizğ buni,

Heqiqiti bar tégide addiy.

Qulule qépida saqlisañmu can,

Teqdir aldida bar kimniñ heddi?

\section{KIZ KALESİ}

Tarihî devirlerde bir padişah

Y1lan görüp düşü bozulmuş

Çok sevdiği kızını koruyup

Bakmışmış uzun yıllar

Boğaziçi'ne bir kale yaptırıp.

Bir gün

Bir balıkçı gemiyi sürüp,

Sepet sepet üzümü yükleyip

Vardığında meyve satmak için

Susayıp üzüm almış kız,

Ancak gözden kaybolmuş gibi saklanıp

Bir sepetten çıkıp bir yılan

Sokmuşmuş kıvrılıp.

$\mathrm{O}$ günden beri

Yerleşmiş bu ad "Kız Kalesi” diye

Efsane deriz biz buna

Basit hakikati var altında

Salyangoz kabuğunda saklasan da can,

Takdir karşısında var kimin haddi? 
Boğda Abdulla'nın başka milletlerin gelenekleri hakkında bilgi sahibi olduğunu gösteren şiirleri vardır. Sentur (Santur) adlı şiirde Pakistanlıların misafir odalarına eski kılıç ve kalkanlarını asma geleneğini hatırlatır: "Mermer tamda qalqan ve qiliç" (Mermer duvarda kalkan ve k1lıç). "Ud Çalidu Pars Dilbiri” (Ud Çalıyor Acem Güzeli) adlı şiirinde ise Fars kültür ve edebiyatına vâkıf olduğu görülüyor.

Boğda Abdulla'nın edebî kişiliğini oluşturan bir başka önemli faktör de şiirlerinde kullandığı temalardır. Aslında bu temalar "anne sevgisi, vatan sevgisi, dostluk, vefa, tabiat sevgisi" gibi bilindik temalardır. Ancak bu temaların ele alınışı farklıdır. Ana bir temanın içinde iç içe geçmiş temalarla karşılaşırız (Azat vd., 2009: 135). Örneğin; “Anican, Anican, Yaşiginin Uzaq" (Anacığım Anacığım Çok Yaşa) adlı şiirin teması ana sevgisidir. Ana, varlığın asıl kaynă̆ıdır. Hayatın asıl kaynağının sembolü olarak görülen "ana", şiirde vatan sevgisi, dostluk, vefakârlık, aşk, muhabbet, milletin istikbali gibi başka temalarla desteklenmiştir:

\section{ANICAN, ANİCAN, YAŞİ́İN UZAQ}

Teşekkur, can berdiñ, yette eza saq,

Héçkimdin kem emes, ya qiñgirir aqsaq.

Tozumas, xorimas eqil, bilimni

$\mathrm{Bu}$ teşna yürekke siñdürgen şundaq,

Anican, anican, yaşig̉an uzaq!

Çiviqni at qilsam söyüvergen sen,

Naxşilar tovlisam köyüvergen sen.

Boz éçip, su tutup alġanda xaman,

"Alqiş al, og̉lum" dep ilham bergen sen,

Anican, anican, yaşiganan uzaq!

Eqideñ büyüktür, rehmitiñ keñdur,

Tebessum eylişiñ quyaşqa teñdur.

Yölensek tevrimes, yiqilmas tağsen,

Yayrisaq keñ bagiriñ lale-çimendur,

Anican, anican, yaşiğan uzaq!

Qoluñġa qarisam qadaqlardin iz,

Mañliyiñ üstide qoruqlardin iz.

İradeñ qaş téşi, qelbiñ yoruñqaş,

Méhnetlik irursen, lékin minnetsiz,

Anican, anican, yaşig̉an uzaq!

\section{ANACIĞIM ANACIĞIM ÇOK YAŞA!}

Teşekkürler, can verdin, yedi aza sağ,

Kimseden eksik değil ya da yamuk aksak

Savrulmaz, yorulmaz aklı ve bilimi

$\mathrm{Bu}$ arzulu yüreğe sindirmiş böylece,

Anacığım anacığım çok yaşa!

Çubuğu at etsem seven sen

Şarkılar söylesem yanan sen

Tarla açıp sulayıp alırken harman

Dua al, oğlum diye ilham veren sen,

Anacığım anacığım çok yaşa!

İnancın büyük, rahmetin geniştir

Tebessümün güneşe denktir

Yaslansak sarsılmaz, yıkılmaz dağsın

Rahatlasak geniş bağrın lale çimendir

Anacığım anacı̆̆ım çok yaşa!

Eline baksam nasırlardan iz

Alnının üstünde kıvrımlardan iz

İraden yeşim taşı, kalbin bir derya

Hep verirsin, ama başına kakmazsın,

Anacığım anacığım çok yaşa! 
Og̉luñmen, nur déseñ közlirimdin al,

Qan déseñ, sugiray, yürikimdin al.

Ketmes yaşliqiñ xuşalliqim şu,

Démesmen özümge boldigiu vabal,

Anican, anican, yaşig̉an uzaq!
Oğlunum, nur istersen gözlerimden al Kan istersen, sökeyim, yüreğimden al.

Gitmez gençliğin mutluluğum o

Demem kendime oldu vebal,

Anacığım anacığım çok yaşa!

Şair, bazı şiirlerinde simgeler kullanarak anlamı okuyucunun idrakine bırakır. Bu tür şiirler, şairin yaşadığı koşullar gereği doğrudan ifade edemediği duyguları ima ettiği şiirlerdir. "Bir Tüp Derex” adlı şiirde geçen "derex, quşqaç" kelimeleri "vatan ve mazlum halk” olarak kullanılmaktadır:

\section{BİR TÜP DEREX}

Quşqaçlarni vetensiz démeñ

Bir tüp derex ulug makani.

Gür qilġanda, pur qilganda hem

Her yapraqta arzu-armani.

Qiyalarniñ şarqiratmisi

Sada birlen bergendek guvah.

Gerçi ular tilsiz yaralġan

Bizçu, lékin

Çidam kétip qilimiz ah-vah.

\section{BIIR ULU AĞAÇ}

Serçeleri vatansız demeyin

Bir büyük ağaç yüce mekânı

Pat diye, pır uçuverdiğinde

Her yaprakta arzuları

Kayaların şakırtısı

Sesiyle şahit olmuş gibi

Gerçi onlar dilsiz yaratılmış

Ya biz, lakin

Dayanamayı ederiz ah vah.

Boğda Abdulla, halk edebiyatının şekil özelliklerinden de yararlanmıştır. Âşık edebiyatı nazım biçimlerinden soru ve cevabı aynı dize içinde olan koşma nazım biçimini (Dilçin, 1983: 305) "Gülehmer” adlı şiirinde kullanarak biçim yönünden de Türk edebiyatıyla ortak bir yönünü göstermiştir:

Dédim:Atiñ ne? Dédi: Gülehmer,

Dédim: Boyuñ ne? Dédi: Gülenber.

Dédim: Yurtuñ ne? Dédi: Kindik Qan

Dédim:Pesliñ ne? Dédi: Yaz, seher

Dédim: Léviñ ne? Dédi: Uz, nepis,

Dédim: Temi ne? Dédi: Gül şéker.

Dédim: Külkeñ ne? Dédi: Zinixim,

Dédim: Textiñ ne? Dédi: Külli yer.

Dédim: Bextiñ ne? Dédi: Öz ecrim,

Dédim: Menzil ne? Dédi: Engüşter.

Dédim: Levziñ ne? Dédi: Levzimdur.
Dedim adın ne? Dedi: Gülehmer

Dedim: Boyun ne? Dedi: Gülenber

Dedim yurdun ne? Dedi: Kindik Kan

Dedim mevsimin ne? Dedi:Bahar, seher

Dedim ağzın ne? Dedi: Güzellik, nefis

Dedim: Tadı ne? Dedi: Gül şeker

Dedim: Gülüşün ne? Dedi: Gamzem

Dedim: Tahtın ne? Dedi: Her yer

Dedim:Bahtın ne? Dedi: Kendi emeğim

Dedim: Durağın ne? Dedi: Yüzük

Dedim: Sözün ne? Dedi: Sözümdür. 
Dédim: Huzur ne? Dédi: Bir kevser.

Dedim: Huzur ne? Dedi: Bir Kevser.

Şiir dili, bir milletin gündelik yaşantısı içinde kullandığı ortak dil içinde özel bir sanat dilidir. Şairin en önemli görevlerinden biri ana dilini sevmesi, en ince ayrıntılarına kadar bilmesi, onu en işlek ve kıvrak biçimde kullanmaya çalışmasıdır (Çetin, 2010: 167). Çağdaş Uygur şiirine damga vuran şairin bir özelliği de dile ve söz sanatlarına olan hâkimiyetidir. Duygularını okuyucuya aktarırken dili ustaca kullanır. Şiirlerinde sık sık atasözleri ve deyimlerden yararlanma yolunu seçer. Teşbih, telmih ve tezat gibi edebî sanatlar dizelerini renklendiren önemli unsurlardandır. "Sentur" adlı şiirinde santurun telini nazlı bir kıza, telin titreşimlerini de gözden titreyerek akan yaşa benzeterek aşk ve musiki arasında bir ilişki kurmuştur. Estetik bir anlayışla kurulan bu ilgiler, şairin edebî sanatları kullanmadaki maharetini göstermesi bakımından önemlidir:

"Sentur tari nazinin qizdek

Titrimekte, yaş kebi gil-gil"

(Santur teli nazlı bir kız gibi

Titremekte, yaş gibi tir tir)

Şair, serbest şiirlerin yanında hece ölçüsüyle de şiirler yazmıştır. Biçim olarak değiş̧ik sayıda dizelerden oluşan bentleri, dörtlükleri, beşlikleri kullanmıştır.

\section{Sonuç}

Boğda Abdulla, şiir dünyasına çocuk şiirleriyle adım atmıştır. Halk edebiyatı motiflerini kullanarak sanatını olgunlaştırmıştır. Şiirlerinde millî özelliklerin yanında yabancı folklorik unsurları da kullanarak evrensel bir çizgiyi yakalamıştır. Şiirlerinde kullandığı dil, okuyucuyu yormayan, estetik bir dildir. Tabiat tasvirlerindeki canlılık, duygularındaki heyecan okuyucu ile arasında dengeli bir köprü kurmasını sağlamıştır. Boğda Abdulla, yeni olanı cesaretle kullanarak Çağdaş Uygur şiirine damga vurmuştur. Şair, kendine has özellikleriyle Çağdaş Uygur şiirinin oluşmasında öncü şahsiyetlerden biridir.

\section{Şiirlerinden örnekler:}

\section{QEDIMIYY YARĠOLDA KEÇKÜZ}

Bir yiraqta tag - seydixan.

Bunda qum - barxan,

Ögzilerni kömüptu boran.

Tökülgen qag̉a cigdisi,

Yiltiz göher, uzarġan.

Çiqip ketti yaz,

\section{TARIHÎ YARGOL'DA GÜZ SONU}

Çok uzakta dağ-Seydihan

Orada kum tepesi

Çatılarını gömer boran

Dökülmüş karga iğdesi

Kök cevher, uzarmış.

Çıkıp gitti yaz 
Déme tebietni halsirigan.

\section{CİGDE DERIXİ}

Qéri cigde derixi,

Heqqiñ bar bolsañ sahipxan.

Şéxiñdiki quşlarg̉a éytqin

Dep qalmisun méni bir méhman.

Men saman tağliridin başlinimen,

Qiyalardin uzaqqa çaçriġan.

Mevhumluqta barçe iz mevhum,

Barmidu biz körmigen topan

Yavayi giyahlar bunda söyümlük,

Sirdişiş pursiti emes héç uzaq.

Teqdir erkiletken kimni aliqanda,

Menzilliriñ emes yasidaq.

Köçken her şeyi ilgiri-axir,

Ebediylik yerniñ astida.

Harginin rohiñğa harg̈in adem,

Sen hazirniñ üstide.

Kel hidiñni, quçaqlayçu bir,

Özüñni untut tamam, şu cennet.

Töküldi méniñ qovzaqlirim

Perişte uniñdin tiriler peqet.

MERMER USTISIIĠA

Esliy soġuq mermer dégen taş,

Göher qoluñda kirer aña can.

Yasarsenmu bivapa dunya-

Hesritini yutsun dep küldan.

KÉÇİDE DÉÑİZĠA NEZER

Dolqun qat-qat,

Aq yalini oynatqandek at,

Çaqirar bir muñluq sada

Çillig̉andek meşuqini pat-pat.

Dolqun némini izdeydig̉andu,

Sada némini sözleydig̉andu,
Deme tabiat yorulmuş.

\section{İĞDE AĞACI}

Yaşlı iğde ağacı

Hakkın var olsan ev sahibi

Dalındaki kuşlara söyle

Demesinler bana bir misafir

Ben Saman Dağları'ndan başlarım

Kayalardan uzağa sıçramış

Soyutlukta bütün iz soyut

Var mıdır görmediğimiz sap

Yabani ot çöp burada sevimli

Sır verme firsatı değil hiç uzak

Kader şımartmış kimi elinde

Durakların daha döşenmemiş

Göçer her şey önce ve sonra

Sonsuzluk yerin altında

Yorgun ruhuna yorgun insan

Sen şimdi üstünde

Gel kokunu kucakla bir

Özünü unut tamam, bu cennet

Döküldü benim derilerim

Melek ondan dirilir lakin

MERMER USTASINA

Aslı soğuk mermer denen taş

Cevher elinde girer ona can

Yapsan da vefası dünya

Hasretini yutsun diye küllük

\section{GECE DENIZZE BAKIŞ}

Dalga kat kat

Ak yelesini oynatan at gibi

Çağırır bir bunalmış ses

Çağırır gibi sevdiğini pat pat

Dalga ne arar

Ses ne söyler 
Dolqun söyse sahilini,

Sada éritip alar köñlini,

Aldimda bir şéiriy tilsimat.

ANA

Toqsanga ulaşti,

Közi xireleşti,

Tonumaydu gahida séni,

Séni çaqiramaqçi bolup

Çaqiridu başqa birini,

Başqa biri çaqirandek.

Toqsan yaz,

Toqsan küz,

Toqsan qiş,

Toqsan etiyaz,

Ötüp ketti

Mañliyig̣a iz sélip,

Ötüp ketti sudek

Emdi,

Tétikliki yoq

Burunqidek.

Körpide yatar,

İşikke qarar,

Sen kelmiseñ bir kün

Köñli yérim bolar,

Közige yaş alar,

Kiçik balidek.

Hey!

Cahanni yaşap tügitip qoydi

Emdi méhmandek!

Köñül nazük nerse,

Kötürelmes gepni

Su-misqal tömürni kötürelmigendek.

Şuña

Taşlima uni,

Untuma uni,
Dalga öpse sahili

Ses eritip alır gönlünü

Önümde bir şiir tılsımı

ANA

Doksana ulaşt1

Gözü donuklaştı

Tanımaz bazen seni

Seni çağıracak olsa

Çağırır başka birini,

Başka birini çağırmış gibi

Doksan yaz,

Doksan güz

Doksan kış,

Doksan bahar

Geçip gitti

Alnına iz bırakıp,

Geçip gitti su gibi

Şimdi

Çabukluğu yok

Eskisi gibi

Pamuk döşekte yatar,

Kapıya bakar,

Sen gelmesen bir gün

Kalbi kırılır,

Gözüne yaş dolar

Küçük çocuk gibi

Hey!

Dünyada yaşayıp gitti

Şimdi misafir gibi

Gönül nazik şey,

Kaldıramaz sözü

Suyun demiri kaldıramadığı gibi

Onun için

Atma onu

Unutma onu, 
Tatliq bilen!

Aççiq-çöçük bilen!

Haldaş,

Muñdaş,

Oggli bolmisa og̉li bol!

Qizi bolmisa qizi bol!

Yuyup qoy,

Çaçlirini tarap qoy,

Dümbisini silap qoy

Putini tutup qoy,

Şundaq qilisañmu

Bir kéçe bergen süti heqqini

Töliyelemsen

Bolup paypétek!

U bolmisa

Sen qéni?!

Men qéni?!

Toqquz ay

Toqquz kün

Toqquz saet

Toqquz deqiqe

Kötürgen bizni qorsiqida,

Aş étip,

Nan yéqip,

Kir yuyup...

Yol yürüp,

Cahan lerzige kelgen tolgiqida...

Çaqmaq çaqqandek,

Boran gürkirigendek!

Biz!

Uniñ bexti,

Arzusi iduq,

Bügüni,

Etisi iduq.

Biz!
Tatlilikla!

Acisiyla tatlisiyla!

Hâlden anla,

Derdini dinle,

Oğlu yoksa oğlu ol

Kız1 yoksa k1zı ol

Y1ka

Saçlarını tara

Sirtını siva

Bacağını tut

Böyle yapsan da

Bir gece verdiği sütün hakkını

Ödeyebilir misin

Koşmaktan yorulsan da!

O olmasa

Sen hani?

Ben hani?

Dokuz ay

Dokuz gün

Dokuz saat

Dokuz dakika

Taşıdı bizi karnında

Yemek yapıp,

Ekmek pişirip,

Çamaşır yıkayıp...

Yol yürüyüp,

Cihanı titreten firtınada...

Şimşek çakar gibi

Boran uğultusu gibi

Biz!

Onun baht1

Arzusuyduk

Bugünü

Yarını idik.

Biz! 
Uniñ qayta tug̉uluşi iduq,

Og̉ul bolup,

Qiz bolup.

Biz!

Uniñga oxşiduq:

Közimiz oxşar,

Qéşimiz oxşar,

Burnimiz oxşar,

Aġzimiz oxşar,

Gül-gülge oxşig̉andek.

Köz nurimiz,

Qara çéçimiz,

Qénimiz

Uniñ idi, uniñ...

Xuddi suniñ béşi bolġandek.

İnsan

Hem eqilliq bolar

Hem nadan

Köyer balisig̀a,

Köymes anisig̀a,

Ana köyer balisiġa:

Séni asmanda uçsa deydu,

Déñizġa şuñguusa deydu,

Töhpeñni körüşni tileydu

Şeyx caynamazda tiligendek.

Tapsa

Bir tal kempüt,

Bir tal alma,

Gélidin ötmes,

Yalġuz yégüsi kelmes

Séni yevalsun deydu,

Séni oruqlap qalmisun deydu,

Kepter baçkisini asiriġandek.

Toqsanġa ulaşti,

Qoliqi égirlaşti,
Onun yeniden doğuşu idik,

Oğul olup,

Kiz olup.

Biz!

Ona benzedik:

Gözümüz benzer,

Kaşımız benzer,

Burnumuz benzer,

Ağzımız benzer,

Gülün güle benzediği gibi.

Göz nurumuz,

Kara saçımız,

Kanımız

Onundu onun...

Tıpkı suyun başı olmuş gibi

İnsan

Hem ak1llı olur

Hem ak1lsız

Sever çocuğunu

Sevmez anasinı

Ana sever çocuğunu

Gökte uçsun der,

Denize dalsa der,

Başarını görmek ister

Şeyhin seccadede duası gibi

Bulsa

Bir tek şeker,

Bir tek elma

Boğazından geçmez

Yalnız yiyesi gelmez

Senin yiyebilmen için

Seni zayıf kalmasın der

Güvercinin yavrusunu koruduğu gibi

Doksana ulaşt1

Kulağı ağırlaştı, 
Çişi çüş̧en,

Béli égilgen,

Béşi ağriydu,

Puti sirqiraydu...

Lékin,

Turgiusi kéler,

Yürgüsi kéler,

Hasisini taşligusi kéler,

Yürgüsi kéler yaş, qiranlardek.

Yer aylinar,

Vaqit uçar,

Bügünniñ bosugisisida

Ete saqlap turar.

Şundaq,

Qériydu barçe:

Ademmu,

Derexmu,

Quşlarmu...

ANICAN ANICAN, YAŞİĠIN UZAQ

Teşekkur, can berdiñ, yette eza saq,

Héçkimdin kem emes, ya qiñgir aqsaq.

Tozumas, xorimas eqil, bilimni

Bu teşna yürekke siñdürgen şundaq,

Anican, anican, yaşig̀an uzaq!

Ulugiluq babida özüñ yégane,

Ésilliq babida özüñ durdane.

Her emsem, şorisam, köksüñ çişlisem,

Vay démey bürküttek turduñ merdane,

Anican, anican, yaşiganan uzaq!

Dem turup yiqilsam, yölidiñ kélip,

Sen ümid üzmidiñ aziliq dep bilip,

"Mañsen bir küni, qedem basqin" dep,

Ömrümni tilidiñ, keldiñ küç bérip,

Anican, anican, yaşig̉an uzaq!
Dişi dökülmüş,

Beli bükülmüş

Başı ağrır

Bacakları sizlar...

Ancak

Duras1 gelir,

Yürüyesi gelir,

Bastonunu atası gelir

Yürüyesi gelir genç yiğitler gibi

Dünya döner

Vakit geçer

Bugünün basamağında

Yarın bekler

Bunun için

Yaşlanır her canlı

İnsan da,

Ağaç da,

Kuşlar da...

\section{ANACIĞIM ANACIĞIM ÇOK YAŞA!}

Teşekkürler, can verdin, yedi aza sağ,

Kimseden eksik değil ya da yamuk aksak

Savrulmaz, yorulmaz aklı ve bilimi

$\mathrm{Bu}$ arzulu yüreğe sindirmiş böylece,

Anacığım anacı̆̆ım çok yaşa!

Yücelik makamında teksin

Asalet makamında incisin

Hep emsem, sorsam, göğsünü dişlesem

Vay demeden kartal gibi durdun mertçe,

Anacığım anacığım çok yaşa!

Nefesim kesilip yıkılsam, destekledin

Sen umudunu kesmedin yaslı deyip

Yürüsen bir gün, adım atın deyip

Ömrümü uzattın, geldin güç verip

Anacığım anacığım çok yaşa! 
Çiviqni at qilsam söyüvergen sen,

Naxşilar tovlisam köyüvergen sen.

Boz éçip, su tutup alġanda xaman,

"Alqiş al, og̉lum" dep ilham bergen sen,

Anican, anican, yaşiġan uzaq!

Eqideñ büyüktür, rehmitiñ keñdur,

Tebessum eylişiñ quyaşqa teñdur.

Yölensek tevrimes, yiqilmas tağsen,

Yayrisaq keñ bag̉riñ lale-çimendur,

Anican, anican, yaşiġan uzaq!

Qoluñga qarisam qadaqlardin iz,

Mañliyiñ üstide qoruqlardin iz.

İradeñ qaş téşi, qelbiñ yoruñqaş,

Méhnetlik irursen, lékin minnetsiz,

Anican, anican, yaşiġan uzaq!

Og̉luñmen, nur déseñ közlirimdin al,

Qan déseñ, sugiray, yürikimdin al.

Ketmes yaşliqiñ xuşalliqim şu,

Démesmen özümge boldigu vabal,

Anican, anican, yaşiġan uzaq!

Su déseñ, aldiñda kevserdek aqay,

Gül déseñ tupraqtin bix urup çiqay.

Méhriñni özümge qilip secdigah,

Séniñ heq söygüñni köñlümde saqlay,

Anican, anican, yaşiġan uzaq!

Seherde oyġansañ, çolpiniñ bolup,

Çolpanni quçaqlap asminiñ bolup,

Ger uçsañ qanatiñ, yürseñ payandaz,

Yelpünsem, söysem hem şamiliñ bolup,

Anican, anican, yaşiğan uzaq!

Çarçisañ hasa qil, yoluñda işlet,

Sen sizġan siziqtin çiqmasmen ebed.

Bügün hem tañlam hem şudur iradem,
Çubuğu at etsem seven sen

Şarkılar söylesem yanan sen

Tarla açıp sulayıp alırken harman

Dua al, oğlum diye ilham veren sen,

Anacığım anacığım çok yaşa!

İnancın büyük, rahmetin geniştir

Tebessümün güneşe denktir

Yaslansak sarsılmaz, y1kılmaz dağsın

Rahatlasak geniş bağrın lale çimendir

Anacığım anacı̆̆ım çok yaşa!

Eline baksam nasırlardan iz

Alnının üstünde kıvrımlardan iz

İraden yeşim taşı, kalbin bir derya

Hep verirsin, ama başa kakmazsın,

Anacığım anacı̆̆ım çok yaşa!

Oğlunum, nur istersen gözlerimden al

Kan istersen, sökeyim, yüreğimden al.

Gitmez gençliğin mutluluğum o

Demem kendime oldu vebal,

Anacığım anacı̆̆ım çok yaşa!

Su istersen önünde kevser gibi akayım,

Gül istersen toprağa kök salıp çıkayım

Güzelliğini kendime kıldım secdegâh

Senin hak sevgini gönlüme koyayım

Anacığım anacı̆̆ım çok yaşa!

Seherde uyansan, Çolpan'in olup

Çolpan'1 kucaklayıp gökyüzün olup

Uçarsan kanadın, yürürsen halı

Dalgalansam, sevsem rüzgârın olup

Anacığım anacı̆̆ım çok yaşa!

Yorulsan dayak yap, yolunda işlet

Senin çizdiğin çizgiden çıkmam hiç

Bugün ve yarın budur isteğim 
He!déseñ Hu! deymen, şu maña rahet,

Anican, anican, yaşiġan uzaq!

Qériliq cismiñga salmisun saye,

Tebiet hökmige unigum kelmes.

Nevriler, çevriler, kökinnevriler...

Qoluñda qatarġa qoşulsun, peves,

Anican, anican, yaşiġan uzaq!

\section{SALG்A TÉŞİ}

Muqeddes derexke çigilgen lata

Arzu-ümidniñ bayraqçisidek

Qoçqar müñgüzi şamalda öñgen,

Epsunsiz dunyaniñ cakarçisidek.

Qaytar ademler tugg-şadig̀a,

Roh yuyulup turidu qumluqta.

Sabiyliktin başlinar nepes,

Gülhan aylangandek altunga otta

Kéçe, qumluqniñ qarañgusida

Kélidu yavayi ceñlerdin sada.

Bu eqildin ġeyri körünüş,

Körsetme Xuda!

Sayniñ téşidek qaqşal baş söñek,

Miñ gez kömülsimu göher bolalmas.

(Belki şu belki emes adavet qisas!)

Bir-birige soqular dehşet,

Huvlaşniñ içide çaçrar ustixan.

$\mathrm{Bu}$ yultuz emes aqqan

$\mathrm{Bu}$ emes yekmu yek meydan.

$\mathrm{Bu}$ inkarniñ xulasisimu?

$\mathrm{Bu}$ törilişniñ cazasimu?

$\mathrm{Bu}$ galibiyetniñ tentenesimu?

$\mathrm{Bu}$ galibiyetniñ mévisimu?

Hemme kömülidiken tebietke,

Hemme siñidiken tebietke.

Yatlişip, davamlişip,
Ne dersen evet derim bu bana hazdır

Anacığım anacı̆̆ım çok yaşa!

Yaşl111k vücuduna etmesin gölge

Tabiat hükmünü kabul edesim gelmez

Torunlar, torun torunları, nesiller...

Elinde siraya eklensin, dolsun

Anacı̆̆ım anacı̆̆ım çok yaşa!

\section{SAPAN TAŞI}

Mukaddes ağaca bağlanan çaput

Umutların bayrağı gibi

Koç boynuzu rüzgârda bozulmuş,

Büyüsüz dünyanın habercisi gibi

Döner insanlar

Ruh y1kanır kumlukta

Çocukluktan başlar nefes

Külhan benzemiş altına ateşte

Gece, kumluğun karanlığında

Geliyor vahşi savaşlardan ses

$\mathrm{Bu}$ akıl dışı manzarayı

Gösterme Allahım!

Derenin taşı gibi yorgun baş kemiği

Bin kez gömülse de cevher olamaz.

(Belki o belki değil kin kısas)

Birbirine vurur dehşet

Gürültünün içinde sıçrar kemik

Bu yıldız değil akan

Bu değil boş meydan

Bu inkârın özeti mi?

$\mathrm{Bu}$ var oluşun cezası mı?

Bu zaferin tantanası mı?

$\mathrm{Bu}$ zaferin meyvesi mi?

Hepsi gömülecek toprağa,

Hepsi sinecek toprağa

Yabancılaşıp, devam edip, 
Ulişidiken ebediyetke.

Boran toxtar, cimiydu hemme,

Aq qumlar laylanmay pakiz.

Yulg̈unniñ çüşlirimu oñ,

Bulginişni bilmeydu hergiz.

Tebiiylik masliqqa çopqet,

Belgisiz yantaqqa yaqqandek şéker.

Kem-kütisi yoq ya artuqi,

Culalangan yaquttek bu yer.

Müñgüzlerni meşel qilġan yurt,

Rivayetliri bir altun açquç.

Saqlanġan çişlarniñ araşlirida,

Yéñilanġandek xémirturuç.

Tiñşa zéminni qulaq yéqip,

Bayqilidu dap ara rétim.

Halsiz emes, tulpar yorgisisi,

Kemtük emes, bicirim.

Yavayi taş öñkürler öçken,

Körüner Miñ Öylerniñ boyiqi ara.

Köçer andin kiyiklerniñ közige

Nohqa tutişidu bara-bara
Ulaşmış ebediyete.

Boran durur, sakinleşir her şey

Ak kumlar kirlenmeden temiz

Ilgının düşleri de sağ

Samuru bilmez herkes

Doğallık uygunluk

Belgesiz

Eksiği yok ya artığ

Cilalanmış yakut gibi bu yer

Boynuzları meşale yapmış yurt

Efsaneleri bir altın anahtarı

Korunmuş dişlerin aralarında

Tazelenmiş gibi maya

Dinle zemini kulak verip

Fark edilir def gibi ritim

Zayıf değil küheylan rahvanı

Eksik değil, tam

Yabanî taş mağaralar yok olmuş

Görünür Bin Evler'in boyası arada

Geçer oradan geyiklerin gözüne

Nuh'a ulaşır gide gide

\section{Kaynaklar}

ABDULLA, B. (2008). Qedimiy Yarg்olda Keçküz. Ürümçi: Şincañ Xelq Neşriyati.

ÇETIN, N. (2010). Şiir Çözümleme Yöntemi. Ankara: Öncü Kitap Yayınları.

DİLÇiN, C. (1983). Örneklerle Türk Şiir Bilgisi. Ankara: TDK Yayınları.

İMAM, H. A. vd. (2011). Uyg்ur Tiliniñ İzahliq Lügiti (Qisqartilmiş 2. Baskı). Ürümçi: Şincañ Qelq Neşriyati.

İNAYET, A. (2000) Uygur Şairi Boğda Abdullah ve Bir Kısım Şiirleri. Türk Dünyası Dil ve Edebiyat Dergisi, 9, 242-250.

MILLETLER NEŞRIYYATİ. (2006). Uyg்ur Edebiyati Tarixi 4-1. Béyciñ: Milletler Neşriyati.

NECIPOVIÇ, N. E. (1995). Yeni Uygur Türkçesi Sözlüğü. (çev. Kurban, İ.). Ankara: TDK Yayınlar1.

QURBAN, V. (1985). Qizil Miñ Öy Resimliri Hikayisi. Ürümçi: Şiñcan Qelq Neşriyati.

SINCON, D. (1997). Uyg்urçe - Ingilizçe Luġet. Ürümçi: Şincañ Qelq Neşriyati.

SULTAN, A. ve ABDURÉHIM, K. (2009). Uyġur Bügünki Zaman Edebiyat Tarixi. Ürümçi: Şincañ Pen-Téxnika Neşriyati. 